\title{
Hydroxyapatite-based materials of marine origin: a bioactivity and sintering study
}

C. Piccirillo ${ }^{1}$, R.C. Pullar ${ }^{2}$, E. Costa ${ }^{3}$, A. Santos-Silva ${ }^{3}$, M.M.E. Pintado, ${ }^{1}$ P.M.L. Castro ${ }^{1}$

1: Centro de Biotecnologia e Química Fina - Laboratório Associado, Escola Superior de Biotecnologia, Universidade Católica Portuguesa, Porto, PORTUGAL

2: Departemento Engenharia de Materiais e Cerâmica / CICECO, Universidade de Aveiro, Aveiro, 3810-193, PORTUGAL

3.: UCIBIO, Faculdade de Farmácia, Universidade do Porto, Porto, PORTUGAL

\section{Abstract}

Single phase hydroxyapatite (HAp) and biphasic material hydroxyapatite/ $\beta$-tricalcium phosphate (HAp/ $\beta$-TCP) were obtained from a marine source (Atlantic cod fish bones).

Here we report a study on the biological properties of these materials, including cytotoxicity, bioactivity and hemocompatibility. Results showed that the materials are not cytotoxic, neither in their powder nor in pellet form; indeed growth of Saos-2 cells was comparable to that of commercial. The hemolysis rate was lower than $2 \%$; hence the materials can be classified as non-hemolytic. Moreover, when immersed in Simulated Body Fluid (SBF), crystal formation was observed on the surface of both materials.

The sintering behaviour of the samples was also studied; both powders showed very high sinterability (density higher than $95 \%$ of the theoretical value).

Overall, these results confirm the suitability of these materials for biomedical applications.

Keywords: hydroxyapatite, bioactivity, hemolysis, sintering.

*: corresponding author, email: cpiccirillo@porto.ucp.pt 


\section{Introduction}

Hydroxyapatite $\left(\mathrm{Ca}_{10}\left(\mathrm{PO}_{4}\right)_{6}(\mathrm{OH})_{2}-\mathrm{HAp}\right)$ is a material belonging to the calcium phosphate family, frequently used for bone and dental implant fabrication due to its high biocompatibility (Szubert, 2014). Other calcium phosphates are also employed in this field, often combined with HAp; tricalcium phosphate $\left(\mathrm{Ca}_{3}\left(\mathrm{PO}_{4}\right)_{2}, \mathrm{TCP}\right)$, for instance, shows good biocompatibility and resorbability in both its $\alpha$ and $\beta$ forms (Dorozhkin, 2010). HAp and other phosphate-based materials are also bioactive, promoting bone growth and formation (Vedakumari, 2014).

Biocompatibility and/or bioactivity can be affected by several parameters; the presence of some minor elements, for instance, can play a crucial role. According to literature data, chlorine ions can increase the bioactivity (Cho, 2014a), while fluorine can have a positive effect on osteoblast growth (Eslami, 2009). Positive ions such as sodium or magnesium can also improve the material's performance (Cho, 2014b; Stipniece, 2014). Moreover, microstructural features such as porosity and surface roughness can also be important (Rocha, 2005; Tran, 2011).

For HAp to be used for bone implant fabrication, its mechanical properties are also crucial; its sintering behaviour, in particular, is important, as this can affect other mechanical properties (Saha, 2009). Sintering can depend on different parameters, which include particle size and shape. The presence of other ions in minor amounts can also have an effect.

HAp in powder form can be prepared by different methods, which generally are based on a chemical reaction between calcium and phosphorus salts. For single phase HAp to be obtained, the $\mathrm{Ca} / \mathrm{P}$ ratio has to be equal to the stoichiometric $\mathrm{HAp}$ ratio (1.67). If $\mathrm{Ca} / \mathrm{P}=1.5$, on the other hand, single phase TCP is prepared (Kannan, 2006). If the $\mathrm{Ca} / \mathrm{P}$ ratio is within these two values, bi-phasic materials of HAp-TCP can be obtained. Additional reagents can also be added to the synthesis, if minor elements like those mentioned above are to be introduced in the HAp lattice (Sheperd, 2012).

HAp can also be obtained from biological sources (Akram, 2014); corals and sea shells, for instance, contain calcium carbonate, which can be converted into HAp with a reaction with an appropriate phosphorus source. Animal and fish bones, however, are a particularly good HAp source, as they already contain it naturally. Therefore, only an extraction process in necessary to obtain HAp, without any chemical reaction (Piccirillo, 2013c). Pig bones, for instance, were successfully converted into HAp (Lü, 2014); several fish have also been used, including swordfish, different species of tuna and sardines 
(Boutinguiza, 2012; Venkantesan, 2011; Piccirillo, 2014). In the majority of cases, the extraction was achieved simply with a treatment at high temperatures (from $700{ }^{\circ} \mathrm{C}$ onwards); in this way, organic matter was removed, leaving only the inorganic phosphate. In other cases, however, different treatments were employed to eliminate the organic matter, such as alkaline hydrolysis or subcritical water process (Venkantesan, 2011; Barakat, 2008). One of the advantages of HAp derived from these sources is that it already contains the minor elements described above, which can have beneficial effects on HAp properties (Akram, 2014).

Calcium phosphate-based materials derived from cod fish bones were previously investigated by the authors of this paper. Results showed that a thermal calcination of the bones led to a HAp/ $\beta$-TCP biphasic material, the proportion of each phase being different depending on the calcination temperature (Piccirillo, 2013c). The formation of $\beta$-TCP was due to the $\mathrm{Ca} / \mathrm{P}$ being lower than 1.67. It was also shown that treating the bones in solution before the calcination could change the composition of the bones and, consequently, of the calcined material. This was because, using suitable solutions, selected ions could be introduced into the lattice structure. A calcium-containing solution, for instance, increased the Ca content in the bones and led to a single phase HAp material; other ions such as sodium or fluorine could also be included in the material. However, biocompatibility of these materials has not yet been demonstrated.

Therefore, in the present work, we report on the biological properties of the HApbased materials produced from cod fish bones as described above. Both biphasic HAp/ $\beta$-TCP and single phase HAp samples were investigated; properties such as bioactivity, cytotoxicity and hemolysis were tested. Moreover, sintering experiments were also performed.

\section{Materials and methods}

\subsection{Sample preparation}

HAp extraction from cod fish bones was previously described in literature (Piccirillo, 2013c). Briefly: fish bones were washed and crushed manually into large pieces up to $1 \mathrm{~cm}$ wide/long. They were then calcined at $700{ }^{\circ} \mathrm{C}$ using a Nabertherm furnace, with a heating ramp of $5{ }^{\circ} \mathrm{C} / \mathrm{min}$ and a calcination time of 1 hour. Samples prepared like this will be indicated as $\mathbf{C B}$ (calcined bones). To increase the calcium content, bones were pre-treated in a $\mathrm{CaCl}_{2}$ solution for 16 hours at $65-70{ }^{\circ} \mathrm{C}$, before calcination. The $\mathrm{CaCl}_{2}$ concentration was 5 times higher than the HAp content in the bone, which was estimated as $70 \%$ weight. Samples prepared in this way will be indicated as $\mathbf{C B C a}$ (calcined bones $\mathrm{CaCl}_{2}$ ). 
The composition of the $\mathbf{C B}$ samples calcined at different temperatures was determined by XRD as reported in literature (Piccirillo, 2013c) and it is shown in Table 1 and Figure 1. For sample CBCa, the composition was always single phase HAp, regardless of the calcination temperature.

Samples prepared in this way were in powder form; in some cases the powder was used without any further treatment, while in others it was compressed in the form of pellet.

\subsection{Sintering studies}

To investigate the sintering process, $\mathbf{C B}$ and CBCa powders were prepared through calcination at $700{ }^{\circ} \mathrm{C}$, as described above. The powder obtained was milled in a Fritsch highenergy planetary ball mill at $200 \mathrm{rpm}$ for 24 hours, in Teflon pots with zirconia balls and isopropyl alcohol (IPA) as a solvent. Previous work (Piccirillo 2013a) showed that after calcination at $600{ }^{\circ} \mathrm{C}$ and milling, the powder had a BET surface area (measured by $\mathrm{N}_{2}$ adsorption) of $\sim 19 \mathrm{~m}^{2} \mathrm{~g}^{-1}$, decreasing slightly to $\sim 15 \mathrm{~m}^{2} \mathrm{~g}^{-1}$ after heating to $700{ }^{\circ} \mathrm{C}$. The average spherical particle size can be estimated from surface area, using the equation $d=$ $(6000 / \mathrm{SA} * \delta)$, where $\mathrm{d}=$ average particle diameter in $\mathrm{nm}, \mathrm{SA}=\mathrm{BET}$ surface area and $\delta=$ density of HAp $\left(3.15 \mathrm{~g} \mathrm{~cm}^{-3}\right)$. This yielded an average particle size of $127 \mathrm{~nm}$ for the powders calcined at $700{ }^{\circ} \mathrm{C}$ and then milled.

The milled powders were dried, and pressed into disc shaped pellets with a diameter of $13 \mathrm{~mm}$ in a uniaxial press at a pressure of $1 \mathrm{ton}$. The pellets were then sintered over a range of temperatures between 900 and $1250{ }^{\circ} \mathrm{C}$, with heating/cooling rates of $5{ }^{\circ} \mathrm{C} / \mathrm{min}$ and dwell time of 2 hours. The density of each sintered pellet was obtained by the geometrical method, calculated from the measured weight $( \pm 0.0001 \mathrm{~g})$ and diameter and height $( \pm 0.01 \mathrm{~mm})$. The maximum (x-ray) densities used for comparison were obtained from the XRD standard XRPDFs 01-010-6315 (HAp = 3.15 $\left.\mathrm{g} \mathrm{cm}^{-3}\right), 01-072-7587\left(\beta-\mathrm{TCP}=3.067 \mathrm{~g} \mathrm{~cm}^{-3}\right)$ and 01070-1454 $\left(\mathrm{ClAp}=3.185 \mathrm{~g} \mathrm{~cm}^{-3}\right)$. The density of a 75\% HAp/25\% TCP mixture for sample CB was estimated to be $3.13 \mathrm{~g} \mathrm{~cm}^{-3}$.

X-ray diffraction (XRD) measurements of the pellets were also performed to see whether any significant change in composition took place during the sintering studies. The diffraction patterns were acquired on a PANalytical X'Pert Pro diffractometer, equipped with a fast RTMS detector (PANalytical PIXcel 1D) and with graphite monochromated $\mathrm{Cu} \mathrm{K \alpha}$ radiation, measured at $40 \mathrm{kV}$ and $40 \mathrm{~mA}$, over a $2 \theta$ range of $20-75^{\circ}$, with a virtual scan step of $0.0167^{\circ}$ and integration time of $100 \mathrm{~s}$. The data was analysed, and semi-quantitative phase 
analysis carried out, on PANalytical HighScore software. The XRD standard patterns used were those named above.

\subsection{Bioactivity tests}

To test the bioactivity, powder samples CB and CBCa obtained by calcination at 700 ${ }^{\circ} \mathrm{C}$ were pressed into pellets as above, which were then heated again at $700{ }^{\circ} \mathrm{C}$ for 1 hour. Each pellet was placed in $20 \mathrm{ml}$ of Simulated Body Fluid (SBF) and left soaking for different lengths of time, up to 28 days; then the pellet was removed, carefully washed with distilled water and dried at room temperature. To observe the possible formation of apatite crystals on the surface of the pellets, they were analysed with Scanning Electron Microscopy using a Hitachi S-4100 at $15 \mathrm{kV}$. Due to their insulating properties, the pellets were sputtered with a gold coating before the analysis. SBF was prepared as reported in literature (Kokubo, 1990).

\subsection{Cytotoxicity tests}

The cytotoxicity was assessed for the materials both in powder and pellet form (micro and macro scale levels, respectively).

To test the powder, human osteosarcoma cells were used. The osteosarcoma cell line, Saos-2 (European Collection of Cell Cultures, UK) were cultured in Dulbecco's Modified Eagle's Medium (DMEM; Sigma-Aldrich, Germany) supplemented with $10 \%$ of heatinactivated fetal bovine serum (FBS; Gibco, South American) and 1\% antibiotic-antimycotic solution (Gibco, GB), in a humidified atmosphere with $5 \% \mathrm{CO}_{2}$ at $37^{\circ} \mathrm{C}$, in 48 -well plates at a concentration of $2 \times 104$ cells $/ \mathrm{ml}, 1 \mathrm{ml}$ per well, for 24 hours. After this time, culture medium was replaced by $1 \mathrm{ml}$ of $0.5 \mathrm{mg} / \mathrm{ml}$ powder suspension, prepared in complete culture medium, and cultures were maintained for 1, 3 and 7 days. Cells on tissue culture polystyrene (TCPS) wells were kept in complete culture medium as control. Three samples per material per time

point were used for each of the four independent experiments conducted. Cell morphology was followed along the time of culture by phase contrast microscopy using a Axiovert 40 (Zeiss, Germany).

After each time point, cells were lysed by osmotic and thermal shock and the obtained supernatant was used for DNA quantification. Cell proliferation was evaluated by quantifying the DNA content along the time of culture using the PicoGreen dsDNA kit (Molecular Probes, USA) according to the instructions of the manufacturer. Fluorescence was read (485 $\mathrm{nm} / 528 \mathrm{~nm}$ of excitation/emission) in a microplate reader (BioTek, USA), and the DNA 
amount calculated from a standard curve. The cell metabolic activity was assessed by the MTS assay, using the CellTiter 96Aqueous One Solution Cell Proliferation Assay (Promega, USA), according to the instructions of the manufacturer. Absorbance was measured at $\lambda=$ $490 \mathrm{~nm}$ using a microplate reader (Synergie HT, Bio-Tek, USA); the results were compared to the control cells cultured in TCPS.

The tests on the powder samples were performed with both $\mathbf{C B}$ and $\mathbf{C B C a}$ samples, calcined at 1100 and $1200{ }^{\circ} \mathrm{C}$.

For the pellets, a cell culture of human bone marrow stromal cells (hBMSCs) was used. hBMSCs were expanded in Alpha-MEM Medium (Alpha-MEM medium; Gibco, Germany) supplemented with $10 \%$ of heat-inactivated fetal bovine serum (FBS; Gibco, South America) and 1\% antibiotic-antimycotic solution (Gibco, GB), in a humidified atmosphere with $5 \% \mathrm{CO}_{2}$ at $37^{\circ} \mathrm{C}$. Differentiation of hBMSCs into osteoblasts was achieved after 21 days of culture in standard osteogenic differentiation medium (alpha-MEM medium supplemented with $10 \mathrm{mM}$ beta-glycerophosphate (Sigma,Germany), $50 \mu \mathrm{g} / \mathrm{ml}$ ascorbic acid (Sigma,Germany) and 10-8 M dexamethasone (Sigma, Germany)).

Each pellet was placed in 6-well plates and 50000 osteoblasts were seeded on top. Cultures were maintained in osteogenic medium for 3, 7 and 14 days. Cells on tissue culture polystyrene (TCPS) wells were kept in osteogenic medium as control. Three pellet samples per material per time point were used in each independent experiment ( 3 experiments were conducted). Cell morphology was followed along the time of culture using an Axiovert 40 (Zeiss, Germany).

DNA quantification was then performed as described above. The analysis of alkaline phosphatase (ALP) activity was performed in the same cell lysates used for the DNA quantification and based on the conversion of p-nitrophenyl phosphate (Sigma,Germany) into p-nitrophenol. In each assay $20 \mu \mathrm{L}$ of lysate were incubated with $80 \mu \mathrm{L}$ of p-nitrophenyl phosphate solution $(0.2 \% \mathrm{w} / \mathrm{w}$, in diethanolamine, Sigma, USA) in a transparent 96 well microplate, at $37^{\circ} \mathrm{C}$, for 45 minutes. The reaction was stopped using $80 \mu \mathrm{L}$ of a $2 \mathrm{M} \mathrm{NaOH}$ (Sigma, USA) and $0.4 \mathrm{mM}$ EDTA (Sigma, USA) solution. Optical density was read at $\lambda=$ $405 \mathrm{~nm}$ using a microplate reader (Synergie HT, Bio-Tek, USA). A calibration curve was previously prepared using p-nitrophenol standard solutions (Sigma, USA) and used to extrapolate the ALP activity values. These values were then normalized against dsDNA results obtained within the same experiments. 
This test was performed for the $\mathbf{C B C a}$ sample; it was prepared calcining $\mathrm{CaCl}_{2}$ treated bones at $700{ }^{\circ} \mathrm{C}$, then compacting the powder into a pellet successively calcined at $700{ }^{\circ} \mathrm{C}$. A comparison with a commercial sample (Biotal) was performed.

\subsection{Hemolysis test}

Hemolysis tests were performed using erythrocytes extracted from blood of healthy volunteers by venipuncture and collected in tubes containing EDTA as anticoagulant. Blood samples were immediately centrifuged at $405 \mathrm{xg}$ for $10 \mathrm{~min}$; plasma and buffy coat were carefully removed and discarded. Erythrocytes were washed three times with phosphatebuffered saline (PBS; $125 \mathrm{mM} \mathrm{NaCl}$ and $10 \mathrm{mM}$ sodium phosphate buffer, $\mathrm{pH} \mathrm{7.4)}$ at $4{ }^{\circ} \mathrm{C}$ and finally resuspended in PBS to obtain an erythrocyte suspension at $10 \%(\mathrm{v} / \mathrm{v})$ hematocrit.

Samples CB and CBCa, calcined at 1100 and $1200{ }^{\circ} \mathrm{C}$, were tested for hemolysis in a concentration of $0.2 \mathrm{~g} / \mathrm{ml}$. An erythrocyte suspension at $10 \%$ hematocrit was used; for every set of experiment $(n=4)$, a control with erythrocytes in PBS only was used. Control and sample tests were run in duplicate. The erythrocyte suspension was incubated at $37{ }^{\circ} \mathrm{C}$ for 3 hours, under gentle shaking.

Hemolysis was determined with UV/Vis spectroscopy, as reported in literature (Ko, 1997); this was done by comparing the absorbance of a sample-containing erythrocyte solution $\mathrm{A}_{\mathrm{S}}$ with the one of a completely hemolysed solution $\mathrm{A}_{\mathrm{H}}$.

To measure $A_{S}$, a $50 \mu \mathrm{l}$ aliquot of the erythrocyte suspension was diluted with 20 volumes of saline solution at the end of the incubation period, and successively centrifuged (1180xg for 10 minutes, at $4{ }^{\circ} \mathrm{C}$ ). The absorption of the supernatant was then read at $540 \mathrm{~nm}$ (maximum hemoglobin absorbance). To measure $\mathrm{A}_{\mathrm{H}}$, a $50 \mu$ laliquot of the suspension was diluted with 20 volumes of distilled water; after centrifugation, the absorption was read at the same wavelength.

The hemolysis percentage was calculated as $\left[\left(\mathrm{A}_{S} / \mathrm{A}_{\mathrm{H}}\right) \times 100\right]$; in the results, it is presented as the difference in comparison to the corresponding control.

\section{Results and Discussion}

\subsection{Sintering behaviour}

To test the sintering behaviour of samples $\mathbf{C B}$ and $\mathbf{C B C a}$, powders calcined at $700{ }^{\circ} \mathrm{C}$ were used. This calcination temperature was chosen to be as low as possible, to avoid 
unnecessary particle growth, while ensuring that all the organic matter was completely removed. Powder CB was found to be $73.2 \mathrm{wt} \%$ HAp and $27.8 \mathrm{wt} \% \beta$-TCP from the XRD pattern, while CBCa was pure HAp (see Figure 1(a) and Table 1). We have shown previously that with increasing heating temperatures, the amount of $\beta$-TCP relative to HAp slightly increases for CB (table 1), while CBCa remains single phase (Piccirillo et al., 2013c). The powders were milled to remove any agglomerations that had formed, to moderate any grain growth that had occurred, and to ensure that any combined phases were well mixed.

XRD patterns of the $\mathbf{C B}$ pellets sintered at the different temperatures are shown in Figure 1(b); it can be seen that both HAp and $\beta$-TCP phases were detected in all pellets. There was no significant variation in the composition ratio of HAp: $\beta$-TCP $=75: 25$ with sintering temperature, i.e. changes were was within the error of the semiquantitative phase analysis method (ignoring line broadening and any amorphous phase present). Furthermore, the difference in density between pure HAp and the 72-25 HAp: $\beta$-TCP mixture is $<1 \%$, and minor variations would not significantly affect the density measurements. Considering this, a relative composition of 75-25 wt\% was considered for the calculation of the relative density of CB. CBCa pellets, on the other hand, were all single phase HAp (XRD patterns not shown).

The measured values of the samples sintered at 900, 1000, 1100, 1200 and $1250 \% 2 \mathrm{~h}$ are given in Table 2, and a photograph of the sintered samples is shown in Figure 2a. It can be seen that as the samples shrink with temperature, they also become darker at $1200{ }^{\circ} \mathrm{C}$ and above, with a bluish-grey colour, and a darker effect in the centre. This is a relatively common phenomenon in ceramics, known as "coring"; it is attributed to oxygen deficiency and reduction of ionic charge on the metal ions in the interior of the sample. Coring has been demonstrated by TEM to be due to oxygen deficiency in pure $\mathrm{TiO}_{2}$ ceramics (Pullar et al., 2009); also in HAp the pale blue colouring has been attributed to oxygen vacancies (Nishikawa, 2001), although no definite evidence for this had been reported to date. It should be noted that the effect is more pronounced in the pure HAp CBCa samples, suggesting the cause is indeed HAp, and not $\beta$-TCP.

An SEM image of the $700{ }^{\circ} \mathrm{C}$ calcined and milled powder $\mathbf{C B}$ is shown in Figure $2 \mathrm{~b}$. This shows the majority of the particles to be smaller than $100 \mathrm{~nm}$, but with a few larger particles up to $200 \mathrm{~nm}$ in diameter. This agrees with the estimated particle size of $\sim 127 \mathrm{~nm}$ obtained from the BET surface area. The sintering behaviour of the samples is shown in figure 3, displaying the data as measured and \% density (fig. 3, right and left $\mathrm{Y}$ axes, 
respectively). At 900 and $1000{ }^{\circ} \mathrm{C}$ the samples have barely begun to sinter, with densities of only $67-77 \%$ of the theoretical maximum. Although the pure HAp CBCa is sintering more rapidly at lower temperatures than the mixed phase $\mathbf{C B}$, the gap between the two samples lessens as the temperature increases, both being over $91 \%$ dense at $1200{ }^{\circ} \mathbf{C}$, and $\mathbf{C B}(97.8 \%)$ being slightly denser than CBCa (96.8\%) after heating to $1250{ }^{\circ} \mathrm{C}$. These data indicate that both samples have good sintering properties, since they both show relative density higher than 95\%; this is a threshold value, above which a bulk material is considered very well sintered.

This is confirmed by the SEM images of samples $\mathbf{C B}$ and $\mathbf{C B C a}$, sintered at $1250{ }^{\circ} \mathrm{C}$ (Figure $4 \mathrm{a}$ and $4 \mathrm{~b}$, respectively). Indeed both micrographs show a well sintered structure, where the grain sizes in both are in the order of $1 \mu \mathrm{m}$ or less, although many of the grains of CBCa do appear to be significantly smaller. The grains of the mixed phase $\mathbf{C B}$ also seem to have a more mottled surface consisting of many nanoscale fissures, and some evidence of stacking crystal planes, neither of which are evident in the pure HAp CBCa.

\subsection{Bioactivity}

To test the capability of $\mathbf{C B}$ and $\mathbf{C B C a}$ samples to form new apatite crystals, pellets of both materials were soaked into SBF for different lengths of time; pellet surface features were monitored by electron microscopy.

Figures 4c) and d) show SEM micrographs of sample CB (pellets heated to $700{ }^{\circ} \mathrm{C}$ ) after soaking in SBF for 3 and 7 days. Before the immersion, grains of up to $1 \mu \mathrm{m}$ size could be seen on the surface of the pellet, and not much grain growth had occurred in the heating process, giving a loosely packed (poorly sintered) material, as was expected as the pellets were only calcined at $700{ }^{\circ} \mathrm{C}$. Separate images of the pellets without growth in SBF are not shown, but they are similar to the uncovered areas seen in fig. 4c). After 1 day in SBF, the formation of a few small apatite crystals (sizes in the order of hundreds of nm) could be observed, and with longer soaking times of 3 days a clear network of crystals had formed an irregular lattice (Fig. 4c), covering most of the surface of the pellet. A complete coverage could be observed after 7 days (Fig. 4d).

By marked contrast, the samples of CBCa showed no significant change after 1, 3 or 7 days in SBF. After an extended period of 21 days they had a partial covering of smaller (hundreds of $\mathrm{nm}$ ) irregular grains that had crystallised on the surface, similar to those observed on sample CB after just 1 day, but more widespread. After 28 days there was some 
evidence that these smaller grains had begun to grow and fuse into one-another, which may be the onset of a network-like lattice seen on sample $\mathbf{C B}$ after 3 days.

These results indicate that the biphasic material (sample CB) shows much higher bioactivity than the single phase HAp (sample CBCa), as apatite formation could be observed with SBF soaking for much shorter periods of time - 7 vs. 28 days for $\mathbf{C B}$ and CBCa samples respectively. These data are in agreement with literature; in fact, Shuai et al. (2013) reported that the rate of apatite crystal formation for biphasic HAp/ $\beta$-TCP materials was higher according to the $\beta$-TCP proportion. This different behaviour can be explained considering that the solubility of $\beta$-TCP is higher than that of HAp; this favours the ion exchange between the material and the SBF solution and, consequently, the apatite crystal formation (Chavan 2010).

The results confirm the bioactivity of these calcium phosphate samples of natural origin; moreover, they show that an improvement in this property can be achieved if a HAP$\beta$-TCP biphasic material is employed.

\subsection{Cytotoxicity test}

The use of SaOs.2 cells is a well-accepted method to test in vitro hydroxyapatite cytotoxicity (Bolelli, 2014; Bernhardt, 2013). The results of the tests for both samples $\mathbf{C B}$ and CBCa calcined at 1100 and $1200{ }^{\circ} \mathrm{C}$ are shown in Figure 5. The cell concentration, calculated through DNA quantification (5a), shows that comparable growth can be observed for all 4 samples. Considering the positive control, a slightly higher cell concentration is observed for the 7 day cultures; the difference with the tested samples, however, is not significant $(\mathrm{p}<$ 0.05). Similar results could be observed for the cell metabolic activity (5b), as no significant different was detected between the various samples.

An additional test was performed on sample CBCa in pellet form, to evaluate the cytotoxicity of the material also at a macroscopic level; a commercial HAp sample was used as positive control. DNA quantification of hBMSC cell is shown in Figure 6(a) for cultures of 3, 7 and 14 days. It can be seen that comparable concentrations can be observed for all three culture times. Figure 6(b) shows the Alkaline Phosphatase Activity (ALP) measured for the 14 day culture of both samples; although the control sample has a slightly higher activity than $\mathrm{CBCa}$, the difference between the two materials is not statistically significant $(\mathrm{p}<0.05)$.

The results of both these tests confirm the non-cytotoxicity / biocompatibility of these phosphate-based samples derived from cod fish bones and makes them suitable to be used as biomaterial components. The osteoblast cells, in fact, are essential for the synthesis and 
formation of extracellular bone matrix; their growth, therefore, is a key parameter to assess the biocompatibility of a biomaterial. Moreover, the ALP activity is a recognised biochemical marker for the osteoblast activity (Sabokar, 1994).

\subsection{Hemolysis tests}

For a material to be used in biomedicine, it is essential to be hemocompatible. The material can come in contact with erythrocytes and, if not hemocompatible, cause them damage, and subsequently hemolysis. It is, therefore, important to test the behaviour of a material when in contact with erythrocytes. Hemolysis tests were performed on samples $\mathbf{C B}$ and CBCa; powders calcined at 1100 and $1200{ }^{\circ} \mathrm{C}$ were analysed, considering the positive results of the cytotoxicity tests described above. According to ASTM (Standard practice for assessment of hemolytic properties of materials, American Society for Testing and Materials Designation: ASTM: F 756-00), if the hemolysis percentage is below $2 \%$ the material is considered non-hemolytic, between 2 and 5\% is referred to as slightly haemolytic, and higher than $5 \%$ as hemolytic. The result of the test is shown in Table 3. All samples showed no hemolytic activity, since the percentage of hemolysis was less than $2 \%$. These results suggested that CB and CBCa samples can be used as biomaterials (Vedakumari, 2014). These results are in agreement with literature, as HAp-based materials have already been reported to be hemocompatible (Stanić, 2011).

\section{Conclusions}

This study showed that HAp-based materials of marine origin have good biological properties; this was observed for both single phase HAp and biphasic HAp/ $\beta$-TCP. In fact, when tested, they showed good bioactivity and hemocompatibility, as well as no cytotoxicity. Moreover, their sinterability was also very good since, when sintered at $1250{ }^{\circ} \mathrm{C}$, their relative density values were higher than $95 \%$.

These results show that these materials have a performance which make them usable in commercial biomedicine products.

\section{Acknowledgments}

This work was through the PEst-C/CTM/LA0011/2013 and PEstOE/EQB/LA0016/2011 programmes, and the iCOD project (Inovadora Tecnologias para a Valorização de Subprodutos do Processamento do Bacalhau, contract QREN AdI I|466). C. 
Piccirillo and R.C. Pullar thank FCT for their research grant (SFRH/BPD/86483/2012 and SFRH/BPD/97115/2013, respectively). 


\section{References}

Akram, M., Ahmed, R., Shakir, I., Ibrahim, W.A.W., Hussain, R., J. Mater. Sci., 49, 14611475 (2014).

Barakat, N.A.M., Khalil, K.A., Sheikh, F.A., Omran, A.M., Gahire, B., Khil, S.M., Kim, H.Y., Mater. Sci. Eng. C, 28, 1381-1387 (2008).

Bernhardt, A., Dittrich, R., Lode, A., Despang, F., Gelinski, M., J. Mater. Sci. Mater. Med., 24, 1755-1766 (2013).

Bolelli, G., Bellucci, D., Cannillo, V., Lusvarghi, L., Sola, A., Stiegler, N., Müller, P., Killinger, A., Gadow, R., Altomare, L., De Nardo, L., Mater. Sci. Eng. C, 34, 287-303 (2014).

Boutinguiza, M., Pou, J., Comesaña, R., Lusquiños, F., de Carlos, A., León, B., Mater. Sci. Eng. C, 32, 478-486 (2012).

Chavan, P., Bahir, M.M., Mene, R.U., Mahabole, M.P., Khairnar, R.S., Mater. Sci. Eng. B, 168, 224-230 (2010).

Cho, J.S., Yoo, D.S., Chung, Y.C., Rhee, S.H., J. Biomed. Mater. Res. A, 102, 455-469 (2014).

Cho, J.S., Um, S.H., Yoo, D.S., Chung, Y.C., Chung, S.H., Lee, J.C., Rhee, S.H., J. Biomed. Mater. Res. B, 102, 1046-1062 (2014).

Dorozhkin, S.V., Biomater., 31, 1465-1485 (2010).

Eslami, H., Solati-Hashjin, M., Tahriri, M., Mater. Sci. Eng. C, 29, 1387-1389 (2009).

Kannan, S., Ferreira, J.M.F., Chem. Mater., 18, 198-203 (2006).

Ko F.N., Hsiao G., Kuo Y.H., Free Radic. Biol. Med., 22(1-2), 215-222 (1997).

Kokubo, T., Kushitani, H., Sakka, S., Kitsugi, T., Yamamuro, T., J. Biomed. Mater. Res., 24, 721-734 (1990).

Lü, X., Wang, J., Li, B., Zhang, Z., Zhao, L., J. Biomed. Mater. Res. A, 102, 2833-2841 (2014).

Nishikawa, H., Mater. Lett., 50, 364-370 (2001).

Piccirillo, C., Pereira, S.I.A., Marques, A.P.G.C., Pullar, R.C., Tobaldi, D.M., Pintado, M.E., Castro, P.M.L., J. Environ. Man. 121, 87-95 (2013).

Piccirillo, C., Pintado, M.M., Castro, P.M.L., Hydroxyapatite and calcium phosphates from marine sources: extraction and characterization. In "Marine Biomaterials: Characterization, Isolation and Applications.” Ed. Kim, S.K., CRC Press (2013).

Piccirillo, C., Silva, M.F., Pullar, R.C., Braga da Cruz, I., Jorge, R., Pintado, M.M.E., Castro, P.M.L., Mater. Sci. Eng. C, 33(1), 103-110 (2013). 
Piccirillo, C., Pullar, R.C., Tobaldi, D.M., Castro, P.M.L., Pintado, M.M.E., Ceram Intern., 40, 13231-13240 (2014).

Pullar, R.C., Penn, S.J., Wang, X., Reaney, I.M., Alford, N.M., J. Euro. Ceram. Soc., 29 419424 (2009).

Rocha, J.H.G., Lemos, A.F., Agathopoulos, S., Valério, P., Kannan, S., Oktar, F.N., Ferreira, J.M.F., Bone, 37, 850-857 (2005).

Sabokar, A., Millett, P.J., Meyer, B., Rushton, N., Bone and Mineral., 27, 57-67 (1994).

Saha, S.K., Banerjee, A., Banerjee, S., Bose, S., Mater. Sci. Eng. C, 29, 2294-2301 (2009).

Shepherd, J.H., Shepherd, D.V., Best, S.M., J. Mater. Sci. Mater. Medic., 23, 2335-2347 (2012).

Shuai, C., Li, P., Liu, J., Peng, S., Mater. Char., 77, 23-31 (2013).

Stanić, V., Janaćković, D., Dimitrijević, S., Tanasković, S.B., Mitrić, M., Pavlović, M.S., Krstić, A., Jovanović, D., Raičević, S., Appl. Surf. Sci., 257, 4510-4518 (2011).

Stipniece, L., Salma-Ancane, K., Borodajenko, N., Sokolova, M., Jakovlevs, D., BerzinaCimdina, L., Ceram. Internat., 40, 3261-3267 (2014).

Szubert, M., Adamska, K., Szybowicz, M., Jesionowski, T., Buchwald, T., Voelkel, A., Mater. Sci. Eng. C, 34, 236-244 (2014).

Tran, N., Webster, T.J., Acta Biomater., 7, 1298-1306 (2011).

Vedakumari, W.S., Priya, V.M., Sastry, T.P., Coll. Surf. B Biointerf., 120, 204-214 (2014).

Venkantesan, J., Qian, Z.J., Ryu, B.M., Thomas, N.V., Kim, S.K., Biomed. Mater., 6, 035003 (2011). 
Table 1. Phase composition for the samples $\mathbf{C B}$ calcined at different temperatures (wt \%).

\begin{tabular}{|c|c|}
\hline Calcination temperature $\left({ }^{\circ} \mathbf{C}\right)$ & HAp : $\beta$-TCP \\
\hline 700 & $73.2: 27.8$ \\
\hline 1100 & $69.7: 30.3^{*}$ \\
\hline 1200 & $67.1: 33.9^{*}$ \\
\hline
\end{tabular}

*: data previously published (Piccirillo et al., 2013b).

Table 2. Shrinkage and density data for sintered CB and CBCa samples between 900-1250

${ }^{\circ} \mathrm{C} / 2 \mathrm{~h}$. Maximum theoretical densities were taken to be $3.13 \mathrm{~g} \mathrm{~cm}^{-3}$ for $\mathbf{C B}(75 \% \mathrm{HAp} / 25 \% \beta$ TCP) and $3.15 \mathrm{~g} \mathrm{~cm}^{-3}$ for CBCa (pure HAp).

\begin{tabular}{|c|c|c|c|c|c|}
\hline \multicolumn{6}{|c|}{ CB } \\
\hline $\begin{array}{l}\text { Sintering } \\
\text { temperature }\end{array}$ & $900 \stackrel{\circ}{C}$ & $1000 \stackrel{\circ}{C}$ & $1100^{\circ} \mathrm{C}$ & 1200 ㄷ & $1250^{\circ} \mathrm{C}$ \\
\hline Height (mm) & 4.16 & 4.55 & 2.90 & 3.83 & 3.00 \\
\hline Diam (mm) & 12.82 & 12.56 & 11.74 & 11.15 & 10.97 \\
\hline $\begin{array}{l}\text { Linear } \\
\text { shrinkage (\%) }\end{array}$ & $1.38 \%$ & $3.38 \%$ & $9.69 \%$ & $14.23 \%$ & $15.62 \%$ \\
\hline Vol $\left(\mathrm{cm}^{3}\right)$ & 0.5370 & 0.5637 & 0.3139 & 0.3738 & 0.2820 \\
\hline Weight (g) & 1.12 & 1.23 & 0.85 & 1.0664 & 0.8623 \\
\hline$\delta\left(\mathrm{g} \mathrm{cm}^{-3}\right)$ & 2.09 & 2.18 & 2.71 & 2.85 & 3.06 \\
\hline$\% \max \delta$ & 66.8 & 69.6 & 86.6 & 91.1 & 97.8 \\
\hline \multicolumn{6}{|c|}{ CBCa } \\
\hline $\begin{array}{l}\text { Sintering } \\
\text { temperature }\end{array}$ & $900 \stackrel{\circ}{\circ}$ & $1000^{\circ} \mathrm{C}$ & $1100^{\circ} \mathrm{C}$ & $1200^{\circ} \mathrm{C}$ & $1250^{\circ} \mathrm{C}$ \\
\hline Height (mm) & 5.49 & 3.80 & 3.38 & 4.89 & 3.09 \\
\hline Diam (mm) & 12.79 & 12.41 & 11.12 & 10.38 & 10.33 \\
\hline $\begin{array}{l}\text { Linear } \\
\text { shrinkage (\%) }\end{array}$ & $1.62 \%$ & $4.54 \%$ & $14.46 \%$ & $20.15 \%$ & $20.54 \%$ \\
\hline $\operatorname{Vol}\left(\mathrm{cm}^{3}\right)$ & 0.5345 & 0.4596 & 0.3283 & 0.4138 & 0.2590 \\
\hline Weight (g) & 1.24 & 1.11 & 0.91 & 1.2186 & 0.7897 \\
\hline$\delta\left(\mathrm{g} \mathrm{cm}^{-3}\right)$ & 2.32 & 2.41 & 2.77 & 2.95 & 3.05 \\
\hline$\% \max \delta$ & 73.7 & 76.5 & 88.0 & 93.7 & 96.8 \\
\hline
\end{tabular}


Table 3. Hemolysis rate (\%) for samples CB and CBCa calcined at 1100 and $1200{ }^{\circ} \mathrm{C}$ at sample concentration $0.2 \mathrm{~g} / \mathrm{ml}$.

\begin{tabular}{|l|l|}
\hline Sample & Hemolysis rate (\%) \\
\hline CB $1100^{\circ} \mathrm{C}$ & $1.75 \pm 0.45$ \\
\hline $\mathrm{CB} 1200^{\circ} \mathrm{C}$ & $1.33 \pm 0.38$ \\
\hline $\mathrm{CBCa} 1100^{\circ} \mathrm{C}$ & $1.40 \pm 0.28$ \\
\hline $\mathrm{CBCa} 1200^{\circ} \mathrm{C}$ & $1.01 \pm 0.22$ \\
\hline
\end{tabular}



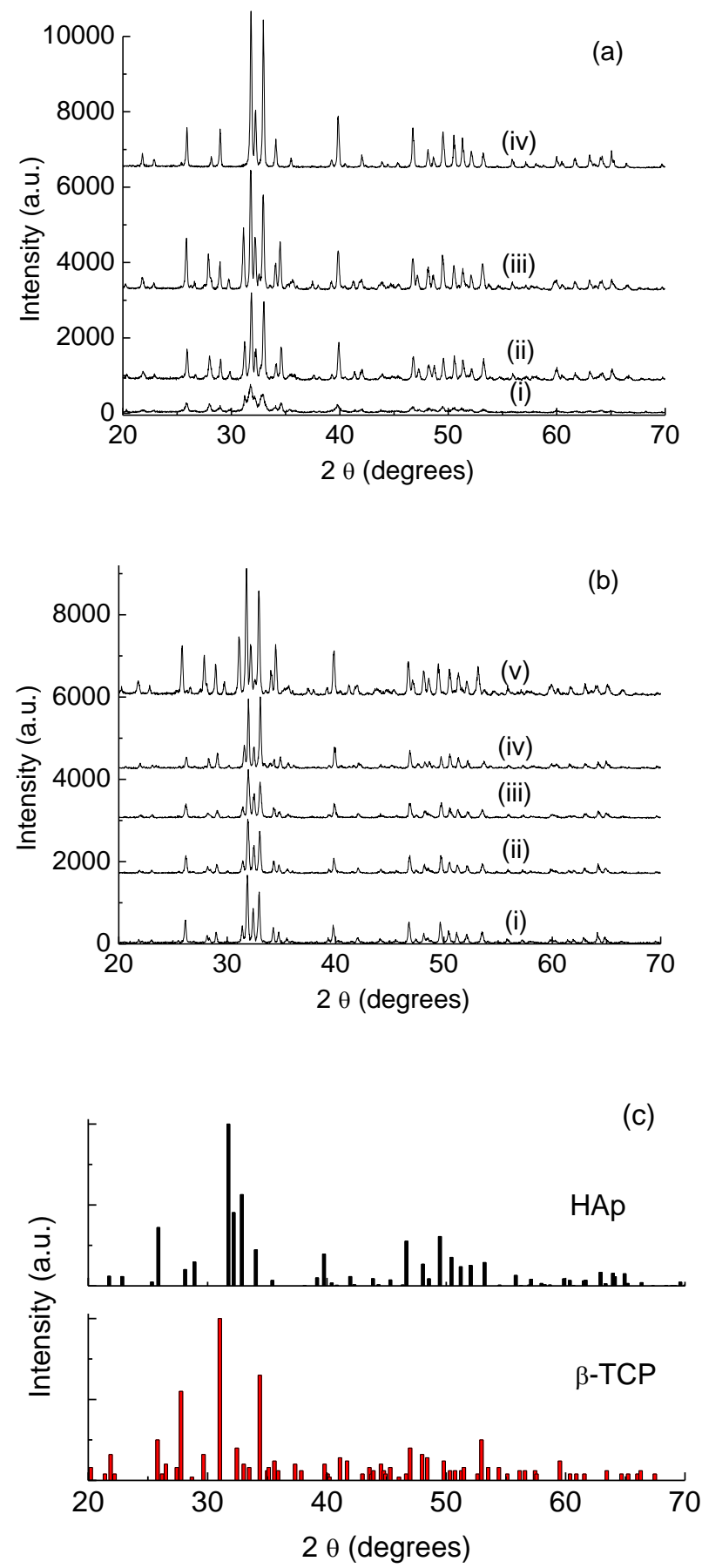

Figure 1. (a) XRD pattern for the samples (i) $\mathbf{C B} 700{ }^{\circ} \mathrm{C}$, (ii) $\mathbf{C B} 1100{ }^{\circ} \mathrm{C}$, (iii) $\mathbf{C B} 1200{ }^{\circ} \mathrm{C}$, (iv) $\mathbf{C B C a}$; (b) $\mathbf{C B}$ pellets calcined at (i) $900^{\circ} \mathrm{C}$, (ii) $1000{ }^{\circ} \mathrm{C}$, (iii) $1100{ }^{\circ} \mathrm{C}$, (iv) $1200{ }^{\circ} \mathrm{C}$, (v) $1250{ }^{\circ} \mathrm{C}$; (c): standard for HAp and $\beta$-TCP . 


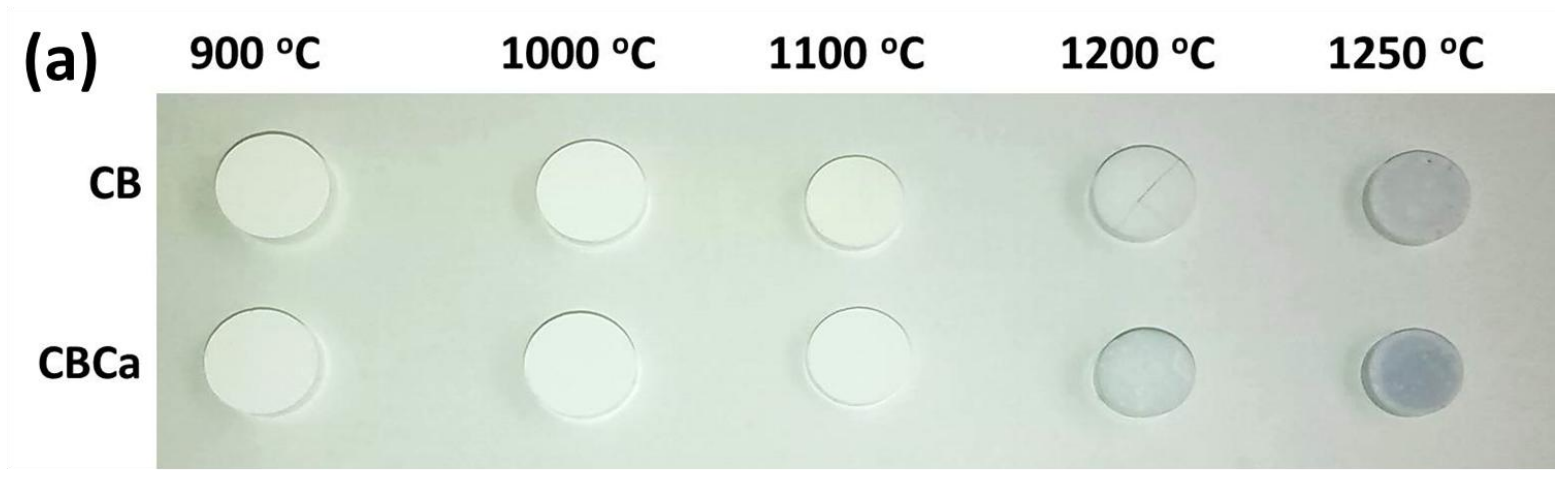

(b)

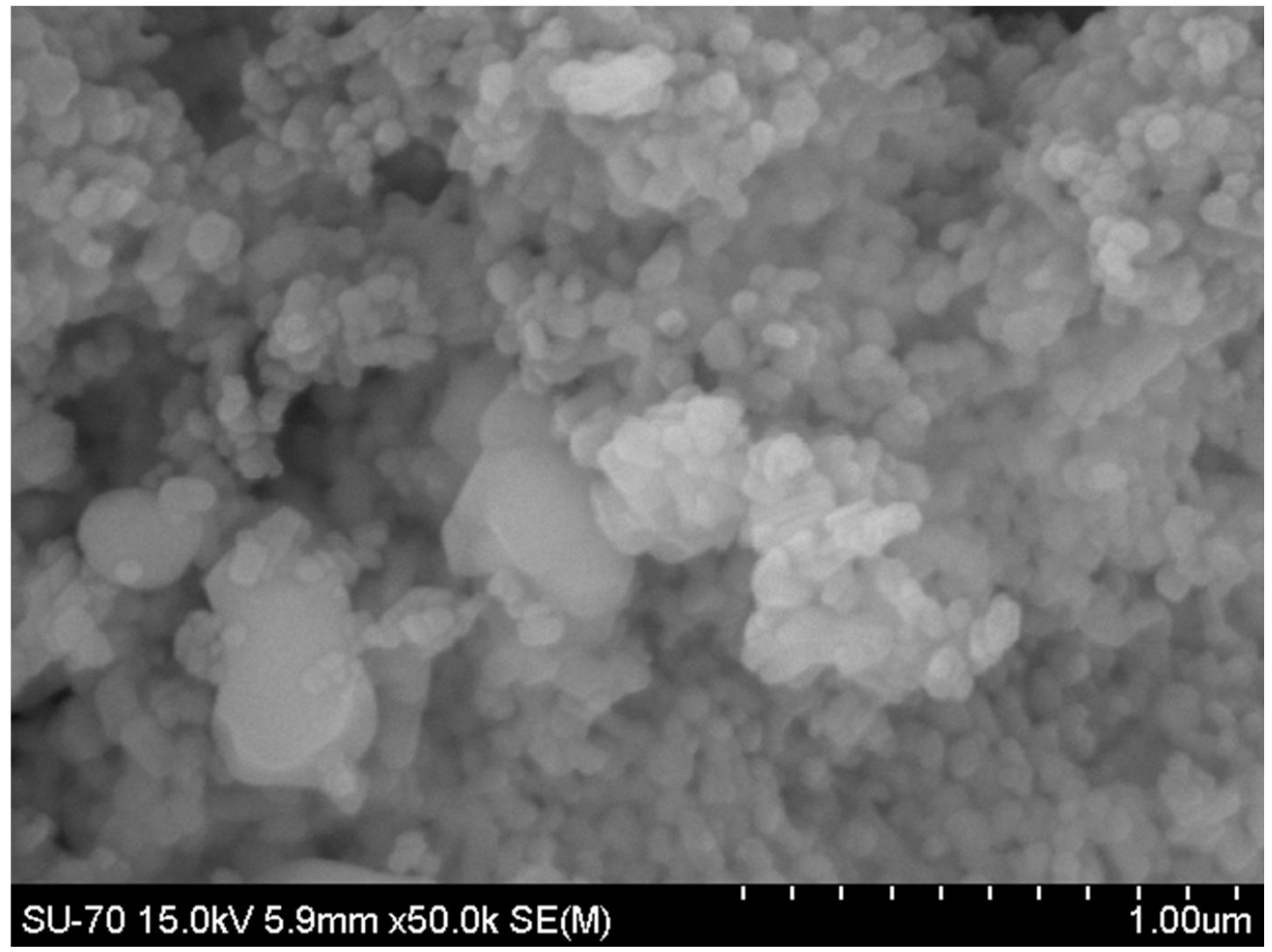

Figure 2. (a) Photograph of $\mathbf{C B}$ and $\mathbf{C b C a}$ sample pellets sintered at different temperatures. (b) SEM image of $\mathbf{C B}$ powder after calcination at $700{ }^{\circ} \mathrm{C}$ and ball milling. 


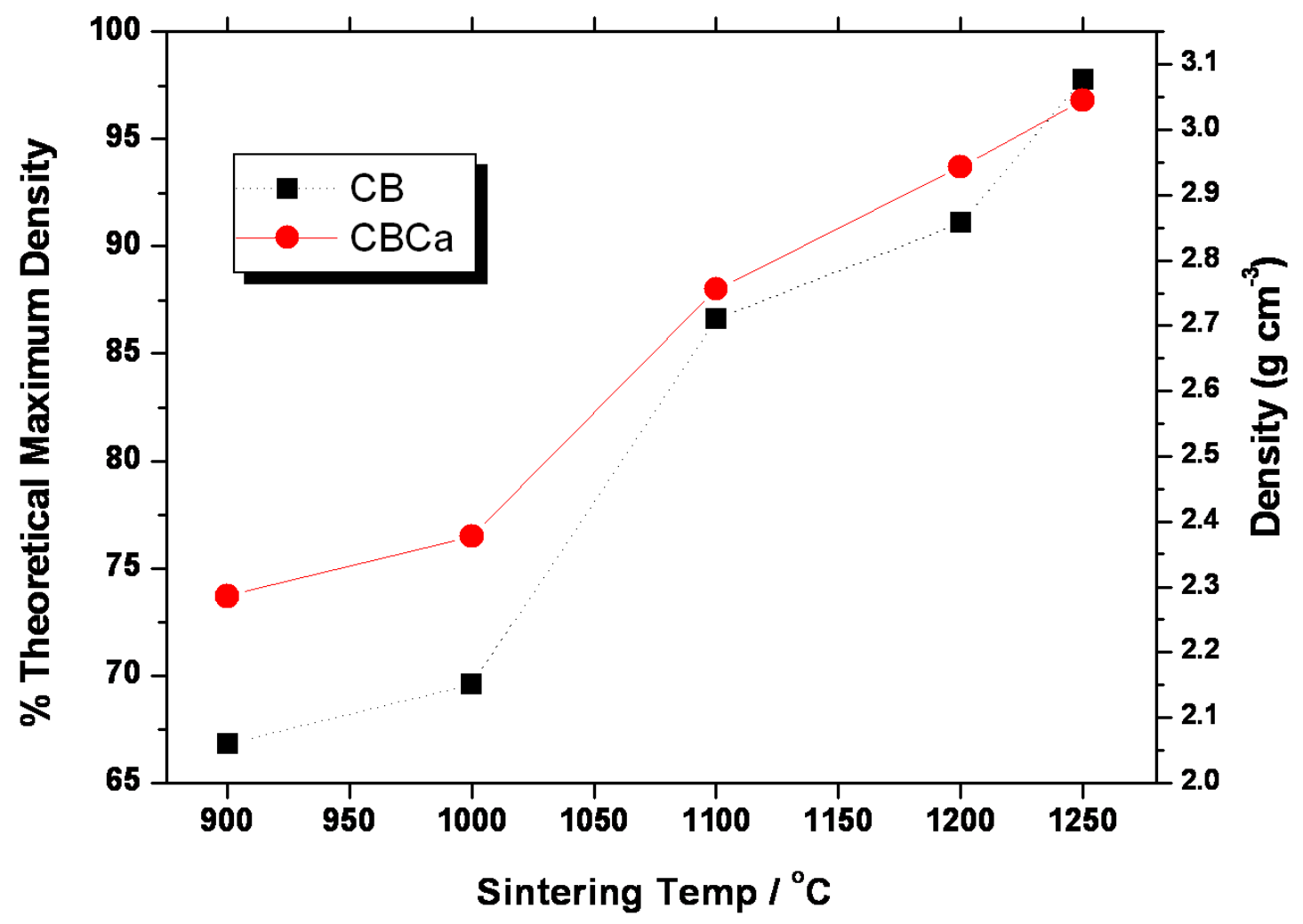

Figure 3. Percentage and measured density of the sintered pellets as a function of the temperature for samples $\mathbf{C B}$ and $\mathbf{C B C a}$. 

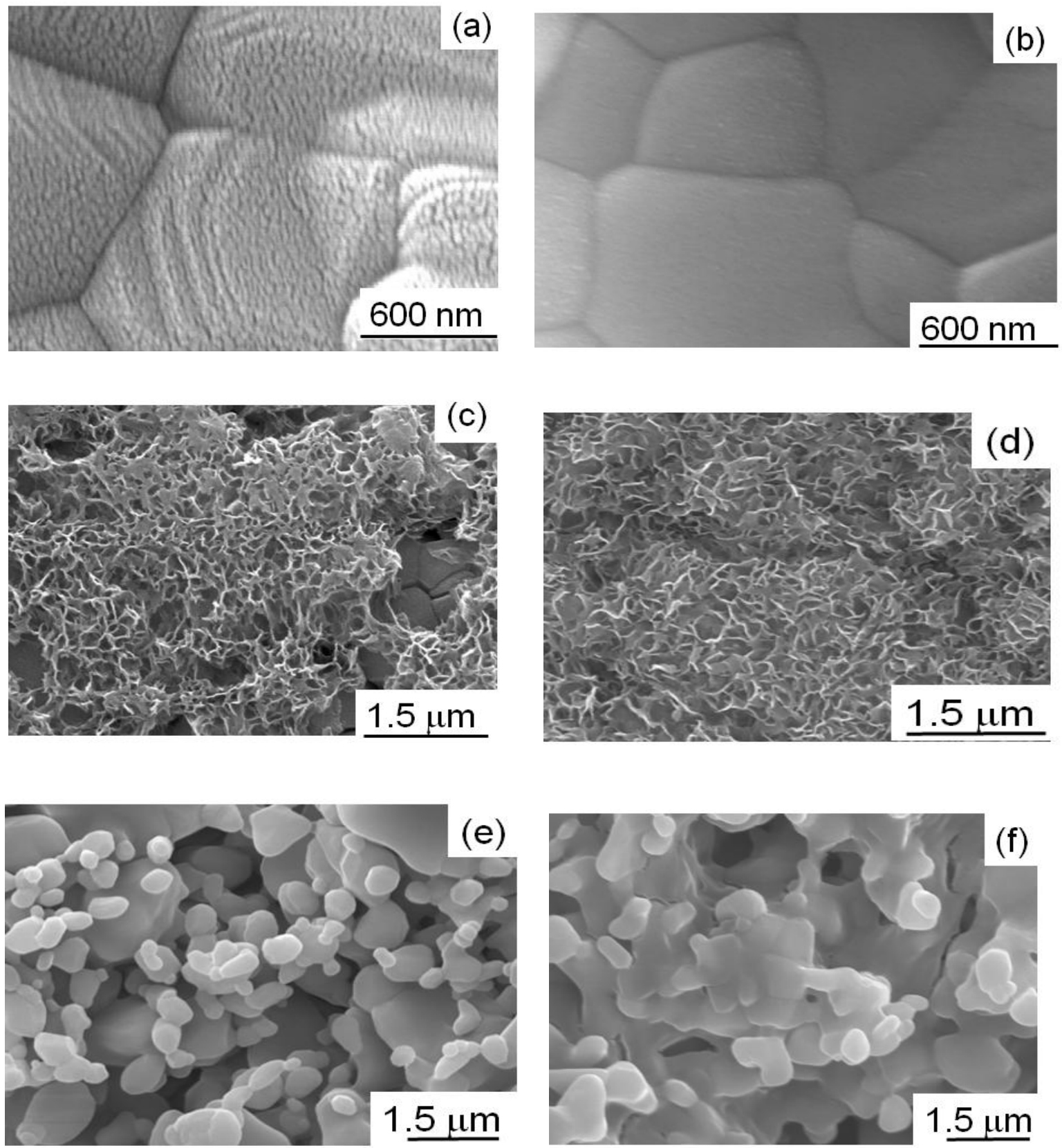

Figure 4. SEM micrographs of: (a) $\mathbf{C B}$ and (b) $\mathbf{C B C a}$ after sintering at $1250{ }^{\circ} \mathrm{C} / 2 \mathrm{~h}$; $\mathbf{C B}$ after (c) 3 and (d) 7 days in SBF; CBCa after (e) 21 and (f) 28 days in SBF. 

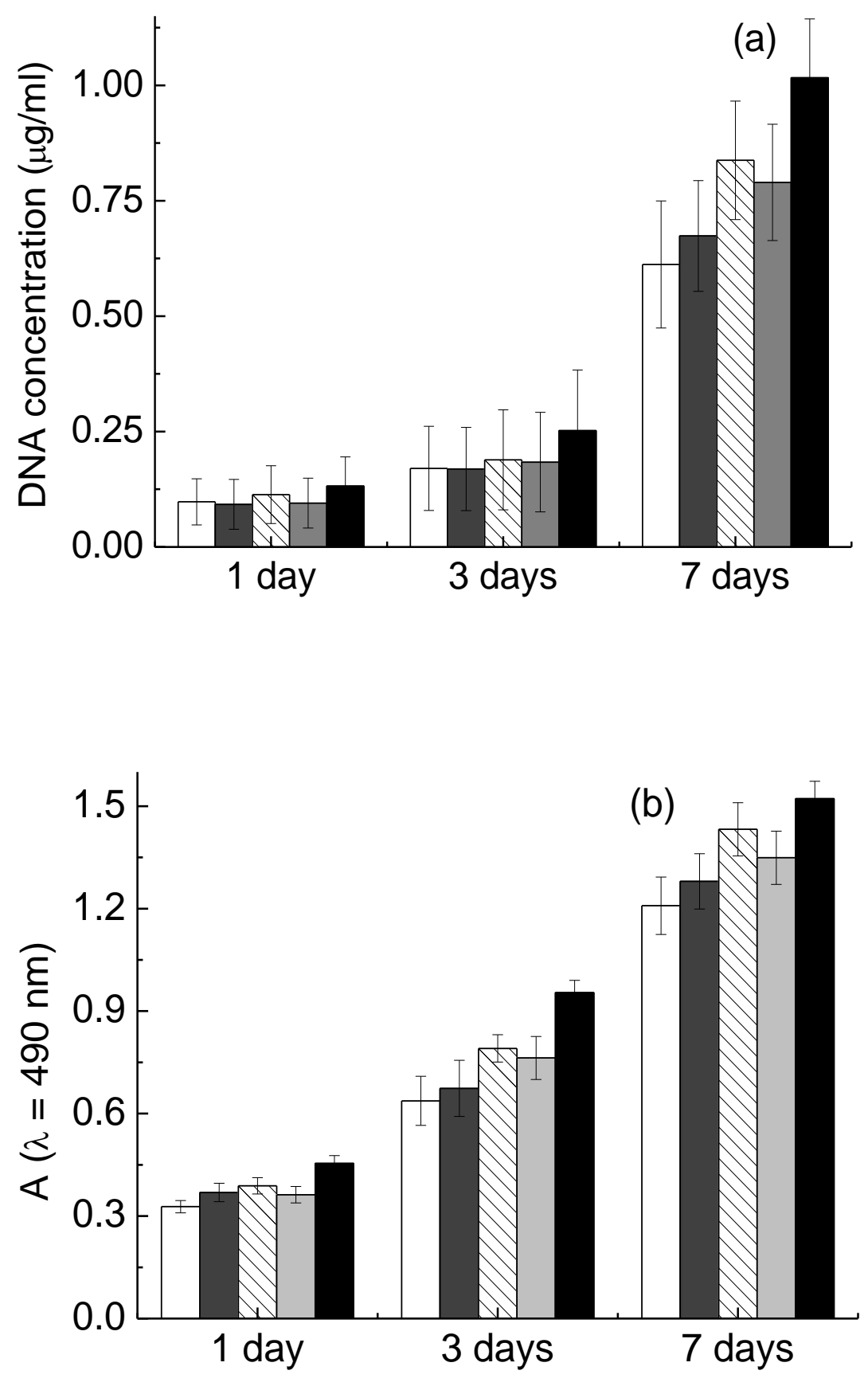

Figure 5. (a) Double strand DNA quantification on SaOs.2 cells; (b) evaluation of cell metabolism. $\square$ : sample $\mathbf{C B}$ calcined at $1100{ }^{\circ} \mathrm{C}$; $\mathbf{m}$ : sample $\mathbf{C B}$ calcined at $1200{ }^{\circ} \mathrm{C}$; $\mathbb{\mathbb { W }}$ : sample CBCa calcined at $1100{ }^{\circ} \mathrm{C}$; $\mathbf{~ : ~ s a m p l e ~} \mathbf{C B C a}$ calcined at $1200{ }^{\circ} \mathrm{C}$; $\mathbf{m}$ : positive control. 

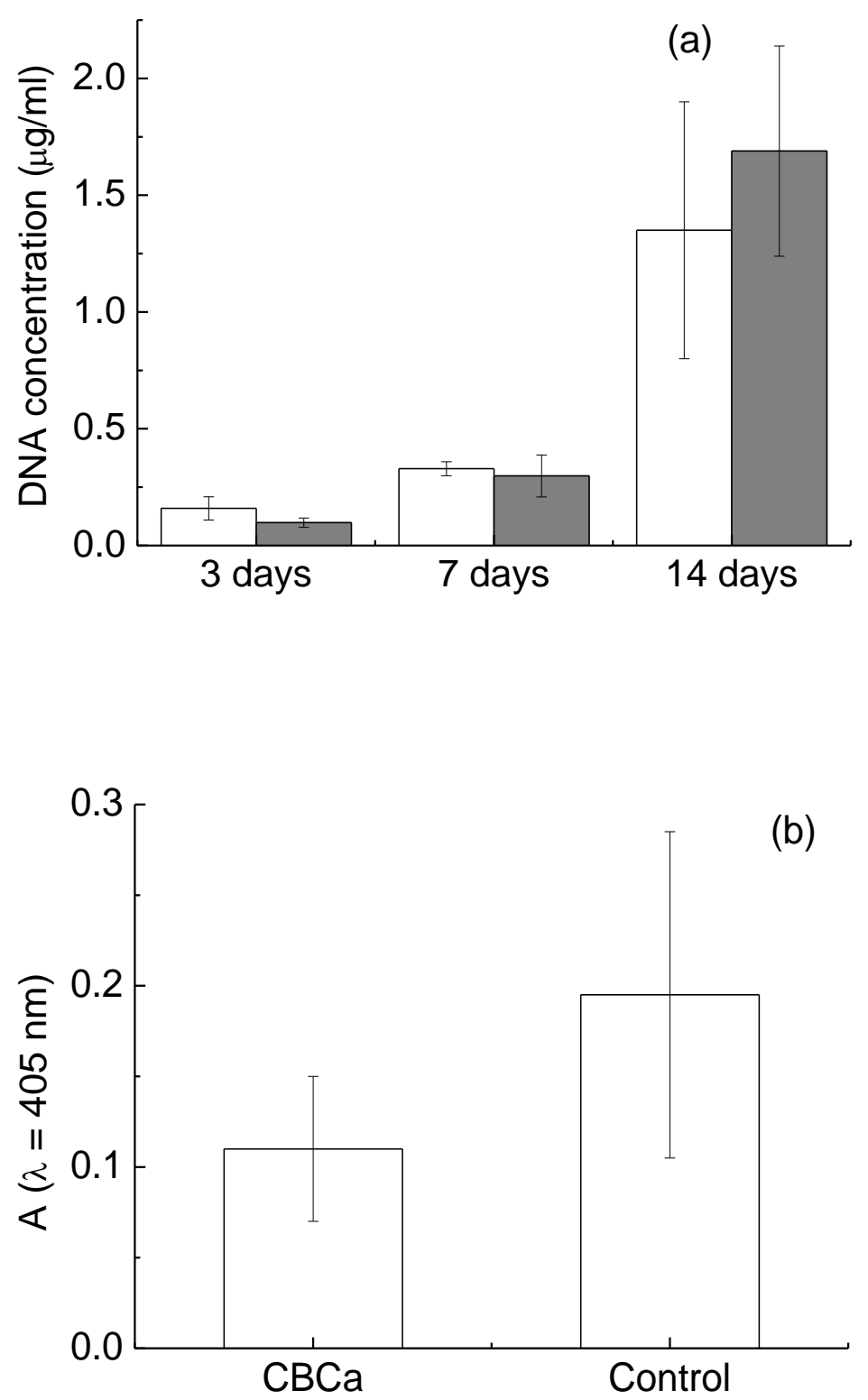

Figure 6. (a) Double stranded DNA quantification of human Bone Marrow Stromal Cells (hBMSC); $\square$ : CBCa sample, $\mathbf{n}$ : commercial control sample. (b) amount of p-nitrophenol phosphate correlated with Alkaline Phosphatase Activity (ALP) in hBMSC after 14 days of culture for CBCa and commercial control sample. 